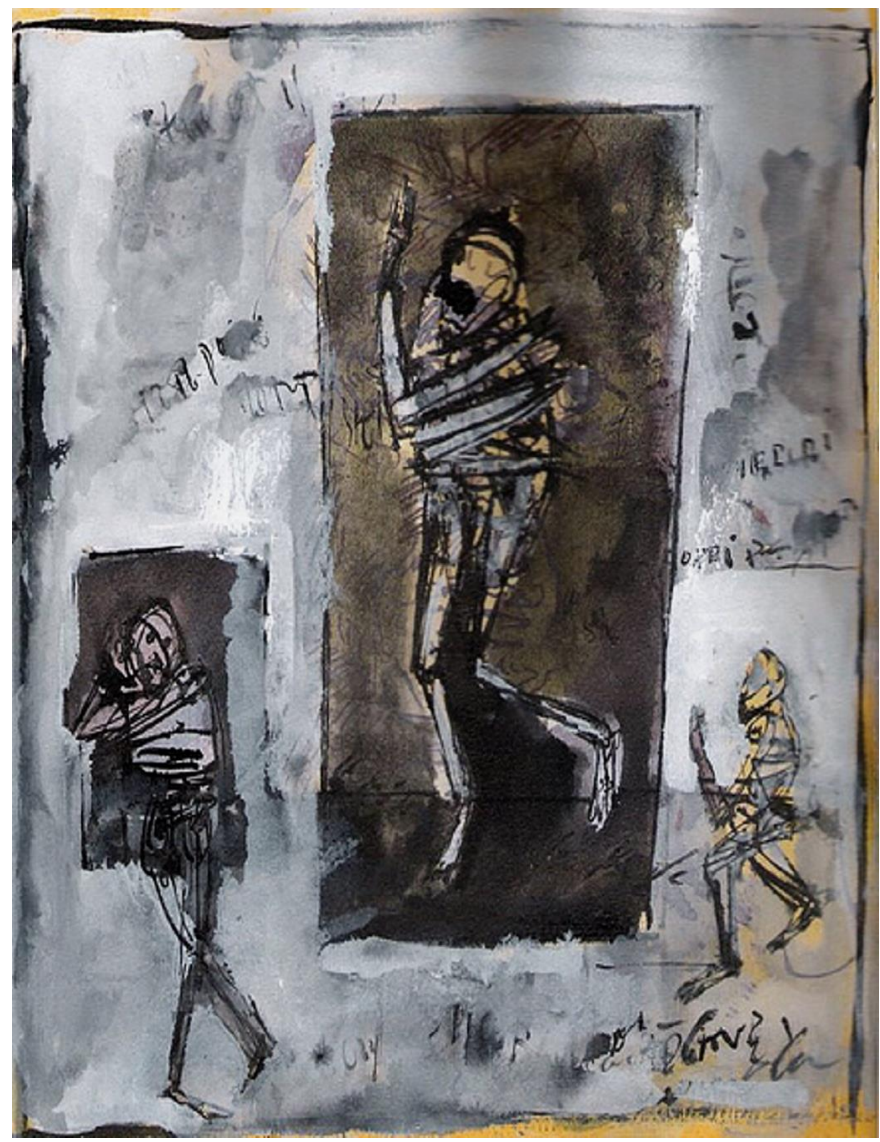

Eskeletons, de Leandro Figueiredo

\title{
A INTEGRAÇÃO ENTRE OS VIVENTES: PELA CONSTRUÇÃO DE NOVOS PARADIGMAS
}

\section{Mariana Licéia Campos de Oliveira}

Licenciada em Letras, FALE/UFMG. Professora de Língua Espanhola, Língua Portuguesa e Literatura Brasileira. Participa do movimento ecológico, vegetariano e de proteção animal. Membro do Setor Verde do Programa A tela e o texto.

\section{Rejane Helena Carvalho Lage Neves}

Formada em Letras, licenciatura plena em língua portuguesa, pela UNI-BH. Cursou extensão universitária em Neurolinguística e Introdução à semiótica. Atualmente, cursa na UFMG, especialização em Ensino de Leitura e Produção de Textos e especialização em Temas Filosóficos. Coordenadora do Setor Verde do Programa A tela e o texto. 


\section{Resumo}

Este artigo apresenta uma abordagem ecológica das relações entre o homem e os outros viventes, discutindo o papel da educação na mudança dos paradigmas que sustentam a vida, no sentido de se construir um mundo mais pacífico e de economia sustentável. Trata-se de um novo olhar sobre a natureza, rompendo-se com a lógica antropocêntrica que, considerando o homem como um ser sobre-natural, encobre seus atos de violência e contribui para a degradação da vida no planeta.

Palavras-chave: ecologia - meio ambiente - educação

Nas últimas décadas ampliou-se, em diversas áreas do conhecimento, a discussão de temas relacionados ao meio ambiente e à ecologia, pois - planeta passa por transformações alarmantes cujas consequências são irreversíveis e preocupam não só ambientalistas e ativistas, mas também intelectuais, políticos, antropólogos, escritores, educadores, estudantes e cidadãos de todo o mundo. Hoje, temos claras evidências da destruição do planeta: em 2007, foi publicado o relatório do Painel Intergovernamental de Mudanças Climáticas (IPCC) da Organização das Nações Unidas (ONU), que responsabiliza o homem pelo aquecimento global e prevê um cenário de catástrofe ambiental (1) .

"Concentrações de dióxido de carbono (CO2), metano e óxido nitroso aumentaram notavelmente como resultado das atividades humanas desde 1750, e agora excedem, em muito, os valores [anteriores]", diz o relatório. "Os aumentos globais na concentração de dióxido de carbono se devem, sobretudo, ao uso de combustíveis fósseis e mudanças no manejo da terra, enquanto o aumento de metano e óxido nitroso se deve primordialmente à agricultura." O documento mostra que, até o final deste século, a temperatura da Terra pode subir de $1,8^{\circ} \mathrm{C}$ - na melhor das hipóteses - até $4{ }^{\circ} \mathrm{C}$. "O derretimento das camadas polares deve fazer com que os oceanos se elevem entre $18 \mathrm{~cm}$ e $58 \mathrm{~cm}$ até $2100 "$, segundo os cientistas. Além disso, tufões e secas devem se tornar mais intensos. O desmatamento e as queimadas da Amazônia tornam o Brasil um dos principais países emissores de gases que contribuem para o efeito estufa.

o consumo inconsequente do atual modelo econômico é uma das práticas que mais degradam a vida na Terra, pois ele é responsável pelo desperdício, pela grande produção de lixo e por outros graves impactos ambientais. As iniciativas para conter esses problemas, como a prática dos três Rs -reduzir, reutilizar, reciclar - ainda têm pouco alcance. A opção pelos denominados "produtos ecologicamente corretos" aquece 0 mercado, ampliando a gama de cosméticos, produtos de limpeza, 
alimentos e outros artefatos fabricados por empresas que divulgam em seus rótulos o respeito ao meio ambiente. Embora essas iniciativas sejam louváveis, elas não trazem mudanças significativas em termos da devastação do planeta. Se, por um lado, surgem discursos e projetos que levantam a bandeira da sustentabilidade e da preocupação ecológica, mostrando práticas importantes e criativas para superar a crise ambiental, por outro, também abundam práticas conservadoras, simplistas e oportunistas. Sendo assim, é urgente refletir a respeito das idéias desustentabilidade, meio ambiente e ecologia, observando como esses assuntos são tratados nos diversos meios, principalmente no meio educacional. Em que paradigmas as ações devem se basear para melhorar as condições de vida no planeta?

A Carta da Terra(2), documento que conclama toda a humanidade a unir esforços para salvar o planeta, define uma sociedade sustentável como aquela que se baseia no respeito à natureza, nos direitos humanos universais, na justiça econômica e numa cultura da paz. O documento chama a atenção para os padrões insustentáveis de produção e consumo que estão causando devastação ambiental, desigualdade social, injustiça, pobreza, violência e conflitos sociais. A Cartapostula que, para cuidar da vida da Terra, cada um precisa empenhar-se na promoção de mudanças de valores, instituições e modos de vida. É necessário "pensar globalmente e agir localmente", para se construir uma sociedade que satisfaça suas necessidades sem comprometer as gerações futuras.

Um dos grandes vilões do desenvolvimento sustentável é o consumismo inconsequente, imposto pelo modo de produção capitalista e responsável pela degradação do ambiente e da vida das pessoas. Assistimos inertes à bestificação de crianças e adultos que, diante de certa televisão, são influenciados a comprar, comprar e comprar. A grande maioria dos programas televisivos busca anular o sujeito pensante, visando apenas ao aumento do lucro próprio e de seus clientes, através de comerciais que induzem os telespectadores desavisados a comportamentos degradantes como o consumo excessivo de bebidas alcoólicas, cigarros, alimentos inadequados etc. A exploração da imagem da mulher - que se torna apenas um objeto desejável ao lado de outras mercadorias que se quer vender - também é um exemplo de desumanização, ou melhor, de desvalorização dos humanos frente ao capitalismo neoliberal, que só busca ampliar mercados e lucros. A maioria dos programas televisivos não se preocupa com princípios éticos e, como os comerciais, eles também incitam o infindável desejo de consumo. Esse modelo de consumismo constitui uma ameaça à sustentabilidade do meio ambiente, à cidadania e à boa educação das pessoas e precisa ser substituído por uma economia que construa uma sociedade sustentável. 
Promover a sustentabilidade e a sobrevivência do planeta são desafios não só do campo ambiental mas também remetem a fatores econômicos, políticos, sociais e educacionais. Tudo isso, sem dúvida, requer uma visão transdisciplinar e integradora, no que se refere à relação entre os seres vivos, exigindo modificações radicais do modo de viver e pensar de um mundo marcado pela excessiva especialização das áreas do conhecimento e por um feroz individualismo. Esse novo jeito de ver o mundo, a partir de um pensamento ecológico, considera que os não-humanos têm um valor em si, independentemente de sua utilidade para os humanos. Esse novo ponto de vista contrapõe-se, portanto, à visão antropocêntrica que desde milênios marca a cultura produzida pela humanidade. Como afirma Morin,

É preciso deixar de ver o homem como um ser sobre-natural. É preciso abandonar o projeto de conquista e dominação da natureza, formulado ao mesmo tempo por Descartes e Marx. Este projeto chegou a ser ridículo a partir do momento em que percebemos que o imenso cosmo permanece fora de nosso alcance. Chegou a ser delirante a partir do momento em que percebemos que o devir prometeico da tecnociência é o que conduz à ruína da biosfera e por isso ao suicídio da humanidade. A divinização do homem deve cessar. Certamente, é necessário valorizar o homem, mas hoje sabemos que somente poderemos valorar verdadeiramente o homem se valorizarmos também a vida, e que o respeito profundo pelo homem passa pelo respeito profundo pela vida(3).

O pensamento ecológico proposto por Morin(4) concebe o ser humano a partir de sua inserção na natureza, e não a partir de sua distinção com respeito aos outros seres. Sendo assim, no âmbito do pensamento ecológico, mais do que garantir a preservação de determinadas espécies animais e vegetais, embora essas questões sejam importantes, faz-se necessário mudar radicalmente as relações dos próprios homens entre si e deles relativamente aos outros seres da natureza. Segundo Bruggüer(5), "meio ambiente" é tradicionalmente concebido como um lugar exterior a nós. A baleia, por exemplo, é considerada um ser do meio ambiente porque está no mar. O mesmo ocorre em relação aos animais selvagens porque vivem na selva. E assim por diante, tudo o que se denomina "recurso natural" é considerado parte da natureza. A expressão "passeio ecológico" desloca a idéia de ecologia para lugares tranquilos e afastados do cotidiano, espaços relacionados ao descanso, ao lazer, às férias. Equivocadamente, nosso entorno imediato e os ambientes construídos não são considerados meio ambiente, o que faz com que o homem dificilmente se considere um elemento da natureza. Esse distanciamento é resultado de uma concepção equivocada, em que a natureza é vista como um manancial inesgotável, que existe apenas para atender às necessidades e aos desejos dos seres humanos. A exploração desenfreada da Mãe Terra exaure seu poder de alimentar a vida, que certamente morrerá junto com ela. 
- tratamento dado aos animais é um dos muitos exemplos da violenta exploração advinda do antropocentrismo. Na maioria das vezes, a preocupação com os animais em extinção revela apenas o desejo de manutenção da biodiversidade e não a defesa da própria vida dos animais ameaçados. O que está em jogo, nesse caso, é o valor de uma certa cadeia genética e genérica, e não o direito à vida dos indivíduos que formam as espécies. Mesmo no caso dos animais domesticados, como cães, gatos, aves, cavalos, vacas, ovelhas etc., vemos que os homens determinam relações de mera utilidade entre eles e os nãohumanos, que lhes servem como objeto de companhia, segurança, terapia, status. Escravizados e oprimidos, esses animais são "posses" nas mãos de seus "donos": são vítimas de infinitos maus tratos, de indiferença e abandono, de discriminação e violentação.

Outros exemplos de tratamento cruel dispensado aos animais dizem respeito à diversão, à alimentação e à experimentação realizadas pelos humanos. Sacrificados lenta ou rapidamente em rodeios, corridas, touradas, rinhas e circos; presos em gaiolas imundas e desconfortáveis; caçados e pescados muitas vezes em competições esportivas; criados em granjas e fazendas como peças industriais; torturados em sessões de vivissecção e testes de laboratórios das universidades e da indústria alimentícia, esses viventes são vítimas de um verdadeiro genocídio. A forma como o homem trata os outros animais e as plantas tem uma íntima relação com a forma como ele trata seus "semelhantes", os outros homens. Isso exige a adoção de um pensamento sistêmico ou ecológico, que considere a intrincada e integrada rede de relacionamentos que une todos os seres.

A partir da teoria de Capra, uma ética ecológica e profunda é

\begin{abstract}
urgentemente necessária nos dias de hoje, e especialmente na ciência, uma vez que a maior parte daquilo que os cientistas fazem não atua no sentido de promover a vida nem de preservar a vida, mas sim no sentido de destruir a vida. Com os físicos projetando sistemas de armamentos que ameaçam eliminar a vida do planeta, com os químicos contaminando o meio ambiente global, com os biólogos pondo à solta tipos novos e desconhecidos de microorganismos sem saber as conseqüências, com psicólogos e outros cientistas torturando animais em nome do progresso científico - com todas essas atividades em andamento, parece da máxima urgência introduzir padrões "ecoéticos" na ciência(6).
\end{abstract}

o pensamento ecológico, baseado em padrões éticos de comportamento, ao propor outra visão de mundo, também inaugura um novo jeito de pensar a educação. Trata-se de uma educação que se ocupa em promover a cultura da paz e um mundo mais sustentável e que, portanto, caminha no sentido de estabelecer um novo olhar do educador e do educando sobre si mesmos e sobre os outros seres, repensando valores, atitudes e comportamentos. Para tanto, a educação deve conduzir à ruptura 
dos tradicionais paradigmas antropocêntricos, entendendo paradigma como "uma constelação de concepções, de valores, de percepções e de práticas compartilhados por uma comunidade, que dá forma a uma visão particular da realidade, a qual constitui a base da maneira como a comunidade se organiza"(7).

Portanto, o processo educativo não pode se restringir a metas cognitivas e anseios mercadológicos. A educação deve investir em processos éticos, afetivos e de responsabilidade social e individual, que levem os indivíduos a construir outras formas de vida, outros valores e novas atitudes. Aeduc-ação implica a promoção do crescimento integral do ser humano - seja ele interno, ou esteja na relação com o outro e com o meio. Temos in-formação demais e inter-açãocooperativa de menos. Segundo Incontri, "a solidão é a neurose do nosso século. Vivemos na era das comunicações e existe uma absurda falta de diálogo. Da rígida e opressiva família patriarcal, passamos ao desencontro e ao abandono."(8). Essa situação não será modificada enquanto os humanos se considerarem os senhores da Terra, fadados a oprimir e destruir os outros viventes em seu próprio benefício. A solidão humana é talvez a principal consequência do isolamento antropocêntrico que nos afastou da natureza, que nos transformou em inimigos dos outros viventes, como se fôssemos feitos de outra matéria e devêssemos permanecer isolados, arrogantes e infelizes, em nossas assépticas redomas de acrílico.

Também Morin(9) alerta para a necessidade de promovermos um conhecimento que apreenda o global, que investigue a complexidade dos objetos a partir de uma subjetividade também complexa como o é a natureza humana. Para ele, o ensinoaprendizagem deve refletir sobre a condição humana em estreita associação com a identidade terrena: tais parâmetros é que vão possibilitar uma educação sustentável, uma educação capaz de integrar, ao invés de segmentar.

Compreendendo a evolução planetária, poderemos perceber que tudo está interligado e que o resultado das catástrofes (naturais ou provocadas pelo homem) afeta a todos os viventes. A atual crise ambiental, econômica e social afeta todo o sistema planetário: "Como seres deste planeta, dependemos vitalmente da biosfera terrestre; devemos reconhecer nossa identidade terrena física e biológica"(10).

As cegueiras paradigmáticas que o autor menciona refletem a inércia dos educadores, os quais refutam a complexidade e privilegiam a redução do objeto de estudo, a fragmentação do conhecimento, a separação entre homens e natureza.

Há dois paradigmas opostos acerca da relação homem/natureza. O primeiro inclui o humano na natureza, e qualquer discurso que 
obedeça a esse paradigma faz do homem um ser natural e reconhece a "natureza humana". O segundo paradigma prescreve a disjunção entre estes dois termos e determina o que há de específico no homem por exclusão da idéia de natureza(11).

Construir novos paradigmas exige a educ-ação do modo de olhar o mundo e do modo de se ver nesse mundo. É preciso incluir-se no todo e reconhecer-se parte dele. Fala-se tanto em pedagogia da inclusão... Incluir-se na natureza não seria a mais importante das inclusões na medida em que combate radicalmente - antropocentrismo? A inclusão é movimento auto-educativo muito mais sutil do que parece, porque ela deve se iniciar no interior de cada um (na alma ou no espírito, para os religiosos e filósofos; na mente ou na psique, para os cientistas; no corpo/espírito ou no dentro/fora, para os derridianos). De qualquer forma, a inclusão é uma atitude que pode se iniciar com uma perspectiva ecológica. O cuidado com os outros seres da natureza flui naturalmente se a noção de "eu" (de indivíduo) for ampliada e aprofundada de tal forma que a proteção da natureza seja sentida e concebida como a proteção de "nós" mesmos (das redes coletivas). A percepção ecológica do mundo deve ser de tal forma internalizada que o respeito do ser humano para com os outros seres e o sentimento de ser parte integrante da teia da vida passem a ser atitudes naturais. Para modificar o mundo é necessário modificar cada ser, pois somos nós que construímos o mundo tal como ele se nos apresenta. Nossas atitudes criam a sociedade em que vivemos a qual, por sua vez, retroage sobre a própria condição humana.

Gadotti(12) postula que não é suficiente mudar o comportamento das pessoas, sendo também necessária uma iniciativa política capaz de reeducar o sistema. De qualquer forma, reeducar o sistema implica mudança das pessoas nele envolvidas enquanto microestrutura social e base do sistema. Uma base bem estruturada e fundamentada é importante condição da sustentabilidade de qualquer sociedade. Voltamos, então, à necessidade de autoeducação e percepção de si como um vivente entre outros tantos, tendo cada um certa função no espaço planetário. É urgente e necessário reconhecer-se como parte de um todo em construção, o qual abrange seus diferentes sem distinção como comenta Morin na citação seguinte:

Tanto no ser humano, quanto nos outros seres vivos, existe a presença do todo no interior das partes: cada célula contém a totalidade do patrimônio genético de um organismo policelular; a sociedade, como um todo, está presente em cada indivíduo, na sua linguagem, em seu saber, em suas obrigações e em suas normas(13).

O filósofo Montaigne(14) dizia que "a presunção é nossa doença natural e original", porque nós nos imaginamos como seres acima de tudo. Por causa de nossa vaidade nos igualamos 
inclusive a Deus, acreditando que Ele nos deu superioridade sobre os outros seres. Para o filósofo, merece forte crítica a ousadia com que o ser humano conclui que os demais viventes são estúpidos.

De resto, qual tipo de competência nossa não reconhecemos nos atos dos animais? Haverá sociedade governada com mais ordem, diversificada em mais cargos e serviços e mais inalteravelmente mantida que a das abelhas? Essa disposição tão ordenada de ações e de funções podemos imaginá-la se desenrolando sem raciocínio e sem previsão? (15)

Montaigne continua sua defesa da inclusão do ser humano na natureza, mostrando que ela "abraçou universalmente todas as criaturas; não há nenhuma que ela não tenha provido plenamente de todos os meios necessários para a conservação da existência"(16). Nesse pensamento, está presente a crença na complexidade e na perfeita ordenação da natureza. Trata-se de um pensamento inclusivo, que busca questionar a autoexclusão da natureza como uma prepotência humana. Rebatendo essa postura, o filósofo declara:

Disse tudo isso para sustentar a semelhança que existe com as coisas humanas, e para reconduzir-nos e juntar-nos aos muitos. Não estamos nem acima nem abaixo do restante: tudo que está sob o céu, diz o sábio, incorre numa lei e num destino igual, "todas as coisas estão encadeadas pelos elos de seu próprio destino". (Lucrécio, V, 874). Há uma diferença, há ordens e graus, mas sob a face de uma mesma natureza(17).

Nessas reflexões, pode-se perceber um conceito abrangente depertencimento dos humanos ao mundo natural. Cabe a nós, educadores, a responsabilidade de levar às crianças e aos jovens a complexidade do pensamento ecológico, dando-lhes oportunidades de pensar sobre relações de cuidado consigo mesmos, com os outros e com o meio ambiente. Trata-se de provocar atitudes de respeito para com a natureza, nos âmbitos do local e do cotidiano, e o reconhecimento da identidade terrena dos humanos.

Já existem vários exemplos de vivências ecológicas dentro e fora das escolas, que estimulam os indivíduos a cuidar dos seres em seu entorno e a assumir, de forma responsável, o papel de agente ecológico em seu meio. Tais vivências, como a simples construção coletiva de uma horta, podem desenvolver sentimentos de alegria e bem-estar, podem estimular uma ética da cooperação e do compartilhamento, podem promover atitudes de preservação e cuidado impulsionando o pensamento sistêmico, onde o conjunto é que garante as condições de construção do sentido. A inter-açãocom os outros animais também é uma experiência fundamental para o desenvolvimento social dos indivíduos humanos - já que a companhia dos animais pode ser terapêutica, com efeitos calmantes e antidepressivos, pois 
estimula a interação social e melhora a autoconfiança e autoestima dos envolvidos. Além disso, a convivência com os outros animais também contribui para que desenvolvamos uma consciência de respeito a nós mesmos e às outras formas de vida. Nesse caso incluem-se não só os animais de estimação, mas também aqueles que se destinam à devoração humana: cuja carne chega a nossos pratos após uma vida degradante e uma morte cruel em abatedouros, granjas e laboratórios da indústria alimentícia. Cuidar da Terra é, portanto, cuidar de seus habitantes, é perceber as necessidades e os sentimentos de outros seres que são diferentes dos humanos, mas que devem ser respeitados como seres de direito.

A partir dessa concepção de ecologia, desenvolve-se a proposta de alfabetização ecológica ou eco-alfabetização(18), que significa compreender os princípios da ecologia - dentre os quais se destacam a interdependência, a cooperação e a parceria - e usá-los para criar comunidades humanas sustentáveis. "Precisamos revitalizar nossas comunidades inclusive nossas comunidades educativas, comerciais e políticas - de modo que os princípios da ecologia se manifestem nelas como princípios de educação, de administração e de política."(19)Assumir-se como parte da natureza é o eixo da alfabetização ecológica, cujos principais objetivos são construir uma sociedade justa para todos (humanos e nãohumanos) e, portanto, garantir a própria sobrevivência da Terra e de seus habitantes.

Mudar os paradigmas da produção de conhecimento significa, portanto, construir uma nova percepção da realidade com todas as implicações éticas, políticas, econômicas e educacionais que isso acarreta. Muitos documentos - como aCarta da Terra, a Declaração Universal dos Direitos dos Animais (UNESCO) e os recentes relatórios da ONU que alertam para o perigo das catástrofes naturais - deixam claro que os valores baseados no consumismo e na exploração do homem e dos outros animais pelo próprio homem devem ser substituídos por novos valores, pois a devastação do planeta e a deterioração da vida já chegaram a proporções assustadoras. Para que a humanidade saia da crise atual é preciso construir um novo mundo, onde a educação, a arte e a cultura estejam vinculadas à garantia de vida na Terra. Esse novo mundo pode existir, a partir do momento em que as teorias acerca da educação necessária à atualidade saiam do papel para a prática pedagógica. Como uma grande rede, tais aprendizagens poderão se expandir, via sujeitos conectados pelo mesmo desejo. A mudança começa em nós. Portanto, mãos à obra! 


\section{Resumen}

Este artículo presenta un abordaje ecológico de las relaciones entre el hombre y los otros vivientes, discutiendo el papel de la educación en el cambio de paradigmas que sostienen la vida, en el sentido de que se construya un mundo más pacífico y de economía más sostenible. Se trata de una nueva mirada hacia la naturaleza, rompiéndose con la lógica antropocéntrica que, considerando al hombre un ser sobre-natural, encubre sus actos de violencia y contribuye a la degradación de la vida en el planeta.

Palabras-clave: ecología, medio ambiente, educación.

\section{Notas}

[1] FERNANDES, 2009. p.1.

[2] ONU. Carta da Terra, 2009.

[3] Es necesario dejar de ver al hombre como un ser sobre-natural. Es preciso abandonar el proyecto de conquista y posesión de la naturaleza, formulado a la vez por Descartes y Marx. Este proyecto ha llegado a ser ridículo a partir del momento en que nos hemos dado cuenta de que el inmenso cosmos permanece fuera de nuestro alcance. Ha llegado a ser delirante a partir del momento en que nos hemos dado cuenta de que es el devenir prometeico de la tecnociencia el que conduce a la ruina de la biosfera y por ello al suicidio de la humanidad. La divinización del hombre debe cesar. Ciertamente, nos es necesario valorar al hombre, pero hoy sabemos que sólo podemos valorar verdaderamente al hombre si valoramos también la vida, y que el respeto profundo hacia el hombre pasa por el respeto profundo hacia la vida.3 Cf. MORIN, 1996. p. 8.

[4] MORIN, 1996. p.1.

[5] BRUGGÜER, 2004.p. 13.

[6] CAPRA, 1996. p. 26.

[7] CAPRA, 1996. p. 19.

[8] INCONTRI, 1998, p.20-21.

[9] MORIN, 2001. p.14.

[10] MORIN, 2001. p.50.

[11] MORIN, 2001. p. 25.

[12] GADOTTI, 2008. p.13.

[13] MORIN, 2001. p.37.

[14] MONTAIGNE, 2000. p.181.

[15] MONTAIGNE, 2000. p.184.

[16] MONTAIGNE, 2000. p.186. 
[17] MONTAIGNE, 2000 . p. 191.

[18] CAPRA, 1996. p. 320.

[19] CAPRA, 1996. p.321.

\section{Referências bibliográficas}

BRUGÜER, Paula. Amigo animal. Florianópolis: Letras Contemporâneas oficina Editorial Ltda., 2004.

CASTRO, Lucas Maroca et al (orgs.). Folhas verdes. Belo Horizonte: Faculdade de Letras da UFMG, Linha Ed. Tela e Texto, 2008.

CAPRA, Fritjof. A teia da vida: uma nova compreensão científica dos sistemas vivos. Trad. Newton Roberval Eichemberg. São Paulo: Cultrix, 1996 .

ONU.Carta da Terra. Disponível em: http://www.cartadaterra.com.br/ctoriginal.htm> Acesso em: 01/03/2009.

FERNANDES, Daniela. Relatório da ONU culpa homem por aquecimento global. Disponível em: <http://www.vegetarianismo.com.br/sitio/index.php?option=com_content\&task=v iew\&id=1080\&Itemid=3>. Acesso em: 10/03/2009.

GADOTTI, Moacir. Educar para uma vida sustentável. In:Pátio Revista Pedagógica. Ano XII, mai./jul. 2008. n. 46. Brasília: Artmed. Ministério da Educação.

INCONTRI, Dora. A educação da nova era. 2. ed. São Paulo: Editora Comenius, 1998 .

MONTAIGNe, Michel de. Os ensaios (Livro II). Trad. Rosemary Costhek Abílio. São Paulo: Martins Fontes, 2000.

MORIN, Edgar. El pensamiento ecologizado. In: Gazeta de antropología. n. 12. $\mathrm{p} .8,1996 . \quad$ Disponível em http://www.ugr.es/ pwlac/G12_01Edgar_Morin.html. Acesso em: 21/04/2009.

- Os sete saberes necessários à educação do futuro. Trad. Catarina Eleonora F. da Silva e Jeanne Sawaya. Rev. técnica de Edgard de Assis Carvalho. 3. ed. São Paulo: Cortez; Brasília, DF: UNESCO, 2001.

UNESCO. Declaração Universal dos Direitos dos Animais. Disponível em: www.apasfa.org/leis/declaracao.shtml. Acesso em: 10/03/2009. 